\title{
ACOUSTIC EXTINGUISHING OF FLAMES DETECTED BY DEEP NEURAL NETWORKS IN EMBEDDED SYSTEMS
}

\author{
Stefan Ivanov, Stanko Stankov \\ Technical University of Gabrovo
}

KEY WORDS: Artificial intelligence, Intelligent Sensor, Firefighting, Acoustic Wave Fire Suppression, Fire Detection, Fire Retardation.

\begin{abstract}
:
This paper presents the application of an intelligent flame and smoke detection platform based on artificial vision using Deep Neural Networks (DNN). An acoustic fire extinguisher can be connected to such a platform. In light of recent research, the use of acoustic technology is an environmentally friendly way of extinguishing flames. One of the advantages is then extinguishing immediately after positive detection of flames or smoke (without unnecessary time delay), which is a new combination in the field of fire protection. The authors contribution is the presentation of the conception of the intelligent acoustic extinguisher and the research work made to accomplish that including algorithms and tests. The main objective of the paper is to present the possibilities of acoustic extinguishing and fire detection using selected deep neural network models in embedded systems.
\end{abstract}

\section{INTRODUCTION}

One of the elements of smart environment and smart agriculture is the desire to use modern technologies in everyday life to improve the standard of living of citizens and increase safety in the broader sense. In recent years, numerous studies have been carried out around the world to analyze the causes of fires, their detection, and the search for fast and efficient extinguishing techniques. Currently, water, hydronets, water mist, sand, fire blankets, and fire hooks are typically used to extinguish flames. A separate group of fire-fighting measures are chemical substances selected according to the class of fire. Popular ones are: extinguishing powders, firefighting foams, halon extinguishers, and carbon dioxide. It is worth noting that some of the extinguishers are withdrawn from production due to their harmful (toxic) effects. Examples include halon fire extinguishers, which are being replaced by pure agents containing a mixture of selected extinguishing gases (halogenated hydrocarbons, inert gases) (P. Niegodajew et al., 2018a; NFPA, 2018).

Global warming is often identified as the cause of fires on a global scale. Sometimes fires are also a consequence of direct, often irresponsible human behavior. In their effects, they cause significant material and immaterial (ecological) losses. Among other things, fires influence environmental devastation, including air pollution, recirculation of heavy metals and radionuclides (Toulouse et al., 2015). In the last decade, severe fires have been reported in many countries such as: France, Greece, and Spain. In 2021, fires covered some areas of Greece and Croatia during the holiday season. In the first half of August 2021, the recorded temperature in Sicily, Italy, reached a record high of 38.8 degrees Celsius. Checks are currently underway to confirm this temperature value. If the result is confirmed, it will mark the highest temperature ever recorded in Europe. Fires have also devastated territories in Australia, Russia, and Canada in recent years, if there was no rainfall for a long period of time. Hence, rainfall statistics for a given area are important (WilkJakubowski, 2018). Due to the enormity of losses caused by fires, there is a need to search for or improve ways to detect and fight fires. It is therefore not surprising that intelligent systems, information technology, and computer science are increasingly used for this purpose. Globally, satellite imagery can be applied to detect fires, with the time scale and spatial resolution being the drawbacks of this technique. For communication, among others, satellite links may be used, especially where there is no adequate technical infrastructure (Wilk-Jakubowski, 2020a, 2020b). Other solutions based on artificial vision and wireless transmission of data from places where fires have been detected are also applied in practice (Šerić et al., 2011; Šerić et al., 2018). Moreover, modern technologies are crucial in the aspect of crisis management. In practice, there is an increase in the expenses incurred for crisis management and an increased interest in using robots for this purpose (Harabin et al., 2020; Wilk-Jakubowski, 2019).

\section{2. "SMART FIREFIGHTER"}

\subsection{The Use of Acoustic Waves for Flame Extinguishing}

The use of acoustic technology to extinguish flames seems to be an interesting issue. Systems applying acoustic waves can be one of the means of fire protection. Based on the analysis of the literature review, it may be concluded that the intensification of research on fire extinguishing with the use of acoustic waves occurred in the early 21 st century. Research on this topic was conducted, among others, by the American agency DARPA (Anthony, 2012). Work was also carried out in many academic and scientific centers around the world. They had resulted in numerous patents (PAT.4872511, 1987; PAT.177478, 1995; PAT.177792, 1995; PAT.10569115, 2015; UM.070441, 2018; PAT.233025, 2018; PAT.233026, 2018; PAT.234266, 2019) and scientific publications, i.e. (Friedman and Stoliarov, 2017; Friedman et al., 2018; Kim and Bae, 2017; Kim et al., 2017; McKinney and Dunn-Rankin, 2007; Niegodajew et al., 2018a, 2018b; Sai and Sharma, 2017; Yi and Bae, 2017). One prototype of a high-power acoustic extinguisher is shown in Figure 1. 


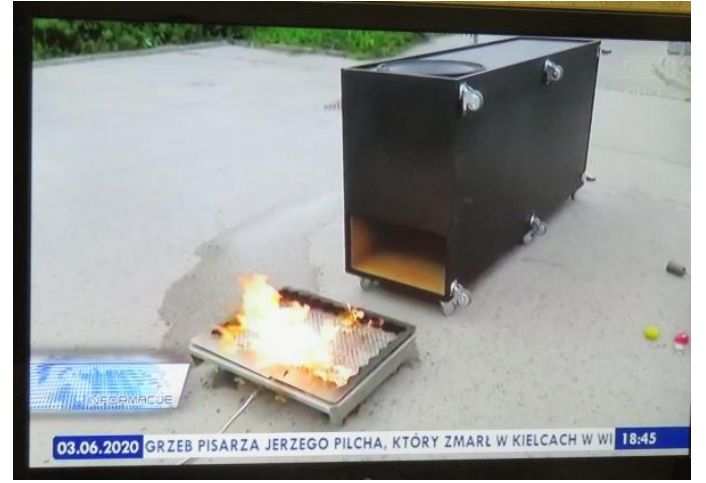

Figure 1. Extinguishing flames with the use of the prototype of the high-power acoustic extinguisher (TVP, "Informacje" from 03.06.2020).

The acoustic extinguisher consists of a generator, modulator, power amplifier, sound source, waveguide, and wiring. When acoustic technology is applied, both modulated and unmodulated waves can be used to extinguish flames. Such extinguishers may generate a low-frequency directional flux with a frequency dependent on the source of the flame. The use of low-frequency waves makes it possible to reach hard-toreach places, and such waves are difficult to suppress (Stawczyk and Wilk-Jakubowski, 2021; Wilk-Jakubowski, 2021). Acoustic waves can find applications for extinguishing burning materials that are hard to extinguish due to their properties. They pass through solids, liquids, and gases, which is a definite advantage of their use. In addition, they do not leave stains (difficult to remove) or emit gases that are toxic to the environment. In practice, the sound pressure capable of extinguishing a flame depends on the electrical power that is applied to the sound source, with a linear increase in sound pressure recorded only within a limited range. From this, its expected value may be determined within a certain range, in a manner well known from computer modelling (Marek, 2013).

The use of modern imaging techniques can effectively detect flames, which makes this technique based on artificial intelligence successfully applicable to the detection of various types of fires, including wildfires (Chen et al., 2004; Chitade and Katiyar, 2010; Madani et al., 2017). A great advantage then is the technology's range in open space, which is much greater than that of typical smoke and temperature sensors. Besides, this technology is resistant to environmental conditions and is much cheaper. For this reason, video detection is considered an opportunity for fast and effective detection of flames and smoke. However, due to the limited range of acoustic technology (it is in its early stages of development), its operation is limited to a few meters. Therefore, acoustic techniques can only be used to extinguish flames at short distances, e.g., indoors, but are not suitable for extinguishing wildfires. Furthermore, it is claimed to be beneficial for extinguishing firebreaks, which can consequently prevent the spread of flames (Wilk-Jakubowski, 2021). Flames originating from gaseous as well as liquid fuels can be extinguished in this way.

\subsection{Intelligent Flame and Smoke Detector}

From a practical point of view, all kinds of artificial vision systems that can be implemented in robots may help firefighters in their work. The use of an acoustic fire extinguisher equipped with an intelligent module that allows it to be activated when flames or smoke are detected is a new approach to traditional fire-fighting methods. Moreover, the extinguishers can work with other systems and smoke and temperature detectors. They may be permanently installed or implement mobile platforms that are equipped with image processing systems. For example, such a sensor, which is part of a fire protection system, can be implemented in an environmentally friendly modular acoustic extinguisher. It may also be a separate device capable of communicating with the fire protection system. The benefits of using such detection include the ability to extinguish flames as soon as they are identified, as activation occurs automatically when flames or smoke are detected. All tests during the research are made because the authors would like to develop a modern autonomous fire extinguisher which uses artificial intelligence and can autonomously take decisions. It is worth emphasizing that experiments with a real acoustic extinguisher will provide data only how well the acoustic extinguisher may extinguish fires. In turn, all other features that are the subject of this article, such as fire detection, motor control, distinguishing between real fire and static image of fire are already tested on the mobile platform. The results for fire detection are the same, because we use the same platforms and custom control electronics. A 3D model of the extinguisher equipped with a flame and smoke detection module is shown in Figure 2.

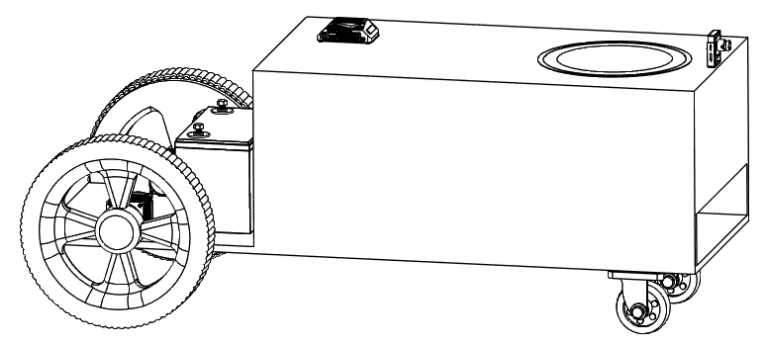

Figure 2. 3D model of the high-power acoustic extinguisher equipped with the intelligent module.

The techniques currently in use are not universal, as it is difficult to select an as-efficient detector for different operating conditions (Wilk, 2009). For this reason, many works can be found in the literature that attempt to evaluate the performance of algorithms (Collumeau et al., 2011; Rudz et al., 2013), but also smoke and fire detection (Çetin et al., 2013; Toulouse et al., 2016). Their performance depends on, among other things, the color of the fire, the smoke, the fuel source, and the environmental factors that affect the image (Toulouse et al., 2015). In practice, fire emits radiation over a wide spectral range. Neural networks for flame and smoke detection may be learned from motionless as well as motion images, as the implementation of artificial intelligence algorithms allows remote flame and smoke detection from both static and nonstatic images (Foley and O'Reilly, 2018; Janků et al., 2018; Kurup, 2014; Szegedy et al., 2013; Zhang, 2018). It is important to note that there are many techniques for detecting fire pixels, as well as color models.

Both visible and infrared band images can be used for detection purposes. When infrared is applied, higher intensity levels of fire pixels are recorded (Martínez-de Dios et al., 2011). Both statistical and empirical models may be found. Some methods use color rules, while some use machine learning based on a dataset containing fire pixels and non-fire pixels. In addition to color and shape detection, dynamic range analysis is also important. Bayes' theorem can be applied for detection. If it is 
used, there is no need for repeated experiments and prior learning of neural networks (Marek, 2021a, 2021b). In practice, the hybrid structure of flame detection, which is based on a mixture of Dirichlet and Gaussian processes, has a beneficial effect on the detection performance. Consequently, the obtained accuracy levels of the algorithms (their efficiency) exceed the $90 \%$ level (Li et al., 2017).

\subsection{Research on the Use of DNN in Embedded Systems}

Intelligent detectors in combination with acoustic technology may be used, among other things, in industry. By applying artificial intelligence, humans can be excluded from the data processing chain. The benefit is then the detection and signalling of fire without the need for human observation (Madani et al., 2017). Some studies show that systems using artificial intelligence and acoustic technology may work together. Recently, several works have appeared in this field. Therefore, ongoing research is directed towards extending the range of acoustic technology, as well as searching for and improving flame detection technology in the visible and infrared bands. DNNs may be used to recognize whether a fire has occurred. Such a system can be implemented in a robotic mobile platform. In practice, various processing schemes and many useful libraries including Matplotlib, OpenCV, TensorFlow, NumPy, and Imutil are used for our physical implementation. An example of the intelligent acoustic extinguisher module constructed by the authors for flame and smoke detection is shown in Figure 3.
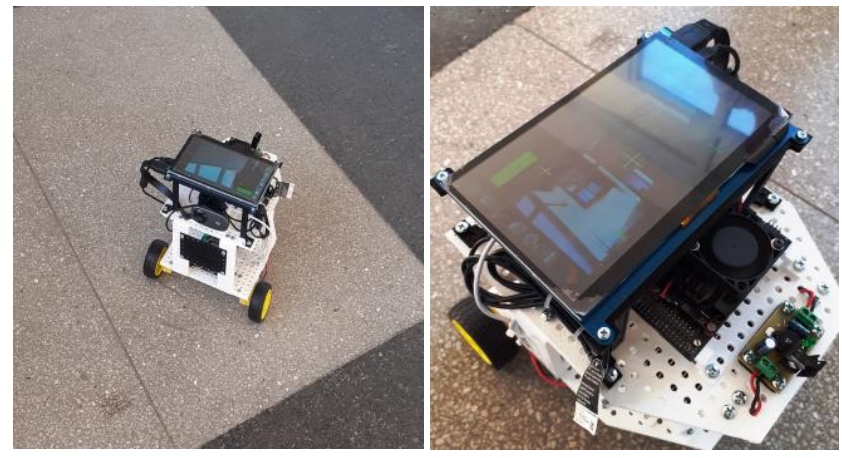

Figure 3. A mobile robot that detects flames and smoke using deep neural networks.

This requires cooperation between a computer module, an image processor, and a camera that is connected to the Jetson Nano (the resolution is $1280 \times 720$ pixels). The system is equipped with an LCD (Liquid Crystal Display) screen to visualize the video stream from the camera and the contours of the fire sources based on the video signal. The project uses an ESP32 microcontroller for the control of the robot. The platform is equipped with additional sensors (temperature, gas, and ultrasonic sensors). The connection to the acoustic extinguisher may be realized by relay modules (control signal: $24 \mathrm{~V}$ ). This robotic mobile platform is applied to the detection of flames and smoke. Work is currently underway for its application in the autonomous acoustic flame extinguishing system. The use of additional interference screens, baffles, and acoustic panels can affect the range of acoustic waves (Niegodajew et al., 2018a). Therefore, the aim is also to reduce losses due to the not fully directional properties of the acoustic extinguisher. Autonomous acoustic extinguishers in the long term may be equipped with intelligent sensors during the construction phase. Regardless of the solution used (stationary or mobile), the results for fire detection on the mobile platform will be the same, as we use the same platforms and custom control electronics.

\section{MODELS OF NEURAL NETWORKS APPLIED TO EMBEDDED SYSTEMS}

In practice, different - adjusted to external factors - flame and smoke detection algorithms can be used. During the research, the authors tested a number of models in embedded systems, made modifications to the neural networks, and applied transfer learning. A Python script enabled operations on images, which were used to train the neural networks. During training, the authors used a batch of images from a fire gathered from the Internet and preprocessed. After rotating, translating, scaling or changing the brightness, an array of 15,000 images was obtained, which were used for training neural networks. It is important that the learning is carried out for different images both in daylight and at night, to make the network as reliable as possible. Of the experiments conducted, the results showed that two models, SSD MobileNet and MASK R-CNN, were best suited for this purpose (depending on the accuracy and speed of image recognition). Therefore, the authors used two types of neural networks for detection purposes:

1. SSD MobileNet - a network with high efficiency but low accuracy for searching small objects. Such a network is dedicated to searching for large objects

2. Mask R-CNN - based on R-CNN. This network allows returning the location of an object and applying a mask to its pixels (lower accuracy than SSD MobileNet)

For practical reasons, it is important that the images are adapted to the size that the neural network input layer specifies (for MobileNet: 300x300, for Mask R-CNN: 800x600).

MobileNet is a neural network architecture that uses deep separable filters. This architecture is applied to embedded applications in devices that have limited computing power. In practice, SSD (Single Shot Detector) may be used for the detection of multiple objects that are present in an image. Feature maps are extracted at the outset through a convolutional network, after which objects are detected through a convolution filter. The combination of both techniques is SSD MobileNet. In turn, the R-CNN mask is a modified (improved) version of the Faster R-CNN. This is due to the fact that the feature mask of the detected object is also returned. Feature maps are extracted from the images at the outset, which are then transmitted by the RPN (Region Proposal Network). On this basis, the coordinates of the bounding boxes are returned. Segmentation allows a mask to be generated on the objects where flames have been detected. The neural network model has many layers. The last of these (connected), are cut and replaced by a new layer trained for detection. This process depends on the number of classes. After training, the networks are subjected to testing. One of the tests was to recognize a video with fire displayed on a computer screen and the quality of a signal from the camera was good enough for successful recognition. The examples of network testing using the robotic platform we constructed (from Figure 3 ) are shown in Figure 4. 


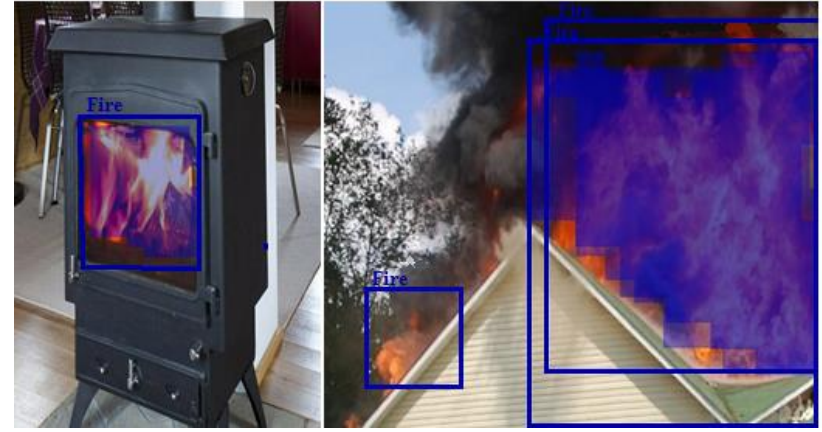

Figure 4. Illustration of detection using deep neural networks.

The algorithm applied to detect flames and smoke is presented below:

1. Initialization of resources on the Jetson Nano

2. Image reading from the camera

3. Scaling of the image to the required values, depending on the input layer of the neural network (SSD MobileNet or Mask R-CNN)

4. Recognition of the image by the neural network and return of the coordinates

5. Movement of the robotic platform so that the platform is directed towards the flame source

6. Activation of the flame extinguishing system

The benefit of using intelligent technologies is the recognition speed, which is equal to $103 \mathrm{~ms}$ for SSD MobileNet and $308 \mathrm{~ms}$ for Mask R-CNN. While the recognition speed for Mask R$\mathrm{CNN}$ is lower, the recognition accuracy is higher (it is more than 90\%). In turn, a recognition accuracy of approximately $80 \%$ was recorded for SSD MobileNet.

Based on the data from the ultrasonic and temperature sensors, a safe proximity distance can be determined to protect the device from heat damage. Recent work has developed control electronics for motors. It is worth noting that the presented artificial intelligence platform using DNNs to detect flames and smoke as part of the acoustic fire extinguisher could be developed and improved in the future. There have been many papers and research projects on this topic in recent years. These are based on a number of DNN architectures that operate with varying effectiveness. Future experiments are therefore planned with other networks and algorithms to support the flame and smoke detection process.

\section{CONCLUSIONS}

In practice, it becomes possible to use multiple technologies, including intelligent sensors for flame and smoke detection. The combination of environmentally friendly acoustic technology and artificial intelligence increases the possibilities of the technologies on offer. In this research, two DNN models were used which work well in embedded systems. Equipping the acoustic extinguisher with the artificial vision system and video cameras enables a rapid extinguishing action to be taken when flames are identified (they can be extinguished as soon as they are detected with virtually no time delay).

\section{REFERENCES}

Anthony, S., 2012: DARPA sound-based fire extinguisher. Extremetech. extremetech.com/extreme/132859-darpa-createssound-based-fire-extinguisher (2 May 2021).
Çetin, A.E., Dimitropoulos, K., Gouverneur, B., Grammalidis, N., Günay, O., Habiboğlu, Y.H., Töreyin, B.U., Verstockt S., 2013: Video fire detection-Review. Digital Signal Processing, 23(6), 1827- 1843. doi.org/10.1016/j.dsp.2013.07.003.

Chen, T., Wu, P., Chiou, Y., 2004: An early fire-detection method based on image processing. Proceedings of International Conference on Image Processing (ICIP '04), 1707-1710. doi.org/10.1109/ICIP.2004.1421401.

Chitade, A.Z., Katiyar S.K., 2010: Colour based image segmentation using k-means clustering. International Journal of Engineering Science and Technology, 2(10), 5319-5325.

Collumeau, J-F., Laurent, H., Hafiane, A., Chetehouna, K., 2011, Fire scene segmentations for forest fire characterization: A comparative study. Proceedings 18th IEEE International Conference on Image Processing (ICIP), 2973-2976. doi.org/10.1109/ICIP.2011.6116285.

Foley, D., O'Reilly, R., 2018: An Evaluation of Convolutional Neural Network Models for Object Detection in Images on Low-End Devices. Proceedings for the 26th AIAI Irish Conference on Artificial Intelligence and Cognitive Science, 350-361. ceur-ws.org/Vol-2259/aics_32.pdf (10 May 2021).

Friedman, A.N., Hughes, J., Danis, P.I., Fiola, G.J., Barnes, C.A., Stoliarov, S.I., 2018: Acoustically Enhanced Water Mist Suppression of Heptane Fueled Flames. Fire Technol., 54, 1829-1840. doi.org/10.1007/s10694-018-0777-0.

Friedman, A.N., Stoliarov, S.I., 2017: Acoustic extinction of laminar line flames. Fire Saf. J., 93, 102113. doi.org/10.1016/j.firesaf.2017.09.002.

Harabin, R., Wilk-Jakubowski, G., Ivanov, S., 2020: Robotics in Crisis Management: a review of the literature. Łódź-Varna, Poland-Bulgaria: University of Social Sciences in Łódź \& Varna University of Management.

Janků, P., Komínková-Oplatková Z., Dulík, T., 2018: Fire detection in video stream by using simple artificial neural network. Mendel, 24(2), 55-60. doi.org/0.13164/mendel. 2018.2.055 (10 May 2021).

Kim, B.-Y., Bae, M.-J., Bae, S.-G., 2017: A study on suitability of sound fire extinguisher in duct environment. Int. J. Appl. Eng. Res., 12, 15796-15800.

Kim, M.-S., Bae, M.-J., 2017: A study on a Fire Extinguisher with Sound Focus. International Information Institute Ltd., 20, 4055-4062.

Kurup, A.R., 2014: Vision Based Fire Flame Detection System Using Optical flow Features and Artificial Neural Network. International Journal of Science and Research, 3(10), 21612168, ijsr.net/search_index_results_paperid.php?id=OCT14677 (8 May 2021).

Li, Z., Mihaylova, L.S., Isupova, O., Rossi, L., 2017: Autonomous, Detection in Videos with a Dirichlet Process Gaussian Mixture Color Model. IEEE Transactions on Industrial Informatics, 14(3), 1146-1154. doi.org/10.1109/TII.2017.2768530.

Madani, K., Kachurka, V., Sabourin, Ch., Amarger, V., Golovko, V., Rossi, L., 2017: A human-like visual-attention- 
based artificial vision system for wildland firefighting assistance. Applied Intelligence, 48, 2157-2179. doi.org/ 10.1007/s10489-017-1053-6.

Marek, M., 2013: Wykorzystanie ekonometrycznego modelu klasycznej funkcji regresji liniowej do przeprowadzenia analiz ilościowych w naukach ekonomicznych. Rola informatyki w naukach ekonomicznych i spolecznych. Innowacje i implikacje interdyscyplinarne. Wydawnictwo Wyższej Szkoły Handlowej im. B. Markowskiego w Kielcach.

Marek, M., 2021a: Aspects of Road Safety: A Case of Education by Research - Analysis of Parameters Affecting Accident. Social Academy of Sciences in Kielce.

Marek, M., 2021b: Bayesian regression model estimation: a road safety. Social Academy of Sciences in Kielce.

Martínez-de Dios, J.R., Merino, L., Caballero, F., Ollero, A., 2011: Automatic forest-fire measuring using ground stations and Unmanned Aerial Systems. Sensors (Basel), 11(6), 63286353. doi.org/10.3390/s110606328.

McKinney, D.J., Dunn-Rankin, D., 2007: Acoustically driven extinction in a droplet stream flame. Combustion Science and Technology, 161(1), 27-48. doi.org/10.1080/ 00102200008935810.

NFPA, 2018. NFPA 2001: Standard on Clean Agent Fire Extinguishing Systems. nfpa.org/codes-and-standards/all-codesand-standards/list-of-codes-and-standards/detail?code=2001 $(10$ May 2021).

Niegodajew, P., Gruszka, K., Gnatowska, R., Šofer, M., 2018a: Application of acoustic oscillations in flame extinction in a presence of obstacle. Journal of Physics (IOP Conf. Series: 1101/2018), doi.org/10.1088/1742-6596/1101/1/012023.

Niegodajew, P., Łukasiak, K., Radomiak, H., Musiał, D., Zajemska, M., Poskart, A., Gruszka, K., 2018b: Application of acoustic oscillations in quenching of gas burner flame. Combustion and Flame, 194, 245-249. doi.org10.1016/j.combustflame.2018.05.007.

PAT.10569115, 2015, Nov. 24, Methods and Systems for Disrupting Phenomena with Waves, by V. Tran, S. Robertson, no application:15/529,262.

PAT.177478, 1995, Dec. 18, Urządzenie do gaszenia płomieni falami akustycznymi (System for suppressing flames by acoustic waves), by S. Wilczkowski, L. Szecówka, H. Radomiak, K. Moszoro, no application: P.311910.

PAT.177792, 1995, Dec. 18, Sposób gaszenia płomieni falami akustycznymi (The method of extinguishing flames with acoustic waves), by S. Wilczkowski, L. Szecówka, H. Radomiak, K. Moszoro, no application: P.311909.

PAT.233025, 2018, Nov. 30, Urządzenie do gaszenia płomieni falami akustycznymi (Device for flames suppression with acoustic waves), by J. Wilk-Jakubowski, no application: P.427999.

PAT.233026, 2018, Nov. 30, Urządzenie do gaszenia płomieni falami akustycznymi (Device for flames suppression with acoustic waves), by J. Wilk-Jakubowski, no application: P.428002.
PAT.234266, 2019, Jan. 18, Urządzenie do gaszenia płomieni falami akustycznymi (Device for flames suppression with acoustic waves), by J. Wilk-Jakubowski, no application: P.428615

PAT.4872511, 1987, Apr. 13, Fire Extinguishing Appliance and Appended Supplementary Appliances, by C.B. Davis, no application 07/040393.

Rudz, S., Chetehouna, K., Hafiane, A., Laurent, H., SéroGuillaume, O., 2013: Investigation of a novel image segmentation method dedicated to forest fire applications. Measurement Science and Technology, 24(7). doi.org/ 10.1088/0957-0233/24/7/075403.

Sai, R.T., Sharma, G., 2017: Sonic Fire Extinguisher. Pramana Research Journal, 8, 337-346.

Šerić, L., Stipaničev, D., Štula, M., 2011: Observer network and forest fire detection. Information Fusion, 12(3), 160-175. doi.org/10.1016/j.inffus.2009.12.003.

Šerić, L., Stipaničev, D., Krstinić D., 2018: ML/AI in Intelligent Forest Fire Observer Network. International Conference on Management of Manufacturing Systems (EAI 2018). doi.org/10.4108/eai.6-11-2018.2279681.

Stawczyk, P., Wilk-Jakubowski, J., 2021: Non-invasive attempts to extinguish flames with the use of high-power acoustic extinguisher. Open Engineering, 11(1), 349-355. doi.org/10.1515/eng-2021-0037.

Szegedy, Ch., Toshev, A., Erhan, D., 2013: Deep Neural Networks for Object Detection. Proceedings of the 26th International Conference on Neural Information Processing Systems (NIPS'13), 2553-2561. doi.org/10.5555/2999792. 2999897.

Toulouse, T., Rossi, L., Akhloufi, M., Çelik, T., Maldague, X., 2015: Benchmarking of wildland fire colour segmentation algorithms. IET Image Processing, 9(12), 1064-1072. doi.org/10.1049/iet-ipr.2014.0935.

Toulouse, T., Rossi, L., Çelik, T., Akhloufi, M., 2016: Automatic fire pixel detection using image processing: a comparative analysis of rule-based and machine learning-based methods. Signal, Image and Video Processing, 10, 647-654. doi.org/10.1007/s11760-015-0789-x.

UM.070441, 2018, Feb. 13, Urządzenie do gaszenia płomieni falami akustycznymi (System for suppressing flames by acoustic waves), by J. Wilk-Jakubowski, no application: W.127019.

Wilk-Jakubowski, G., 2019: Normative Dimension of Crisis Management System. Organizational and Economic Aspects. Wydawnictwo Społecznej Akademii Nauk.

Wilk, J., 2009: Techniki cyfrowego rozpoznawania krawędzi obrazów. Wydawnictwo Stowarzyszenia Współpracy PolskaWschód. Oddział Świętokrzyski.

Wilk-Jakubowski, J., 2018: Measuring Rain Rates Exceeding the Polish Average by 0.01\%. Pol. J. Environ. Stud., 27(1), 383-390. doi.org/10.15244/pjoes/73907. 
Wilk-Jakubowski, J., 2020a: A review on information systems engineering using VSAT networks and their development directions. Yugoslav Journal of Operations Research, OnlineFirst 00, 15-15. doi.org/10.2298/YJOR200215015W.

Wilk-Jakubowski, J., 2020b: Overview of broadband information systems architecture for crisis management. Informatyka, Automatyka, Pomiary w Gospodarce i Ochronie Środowiska, 10(2), 20-23. doi.org/10.35784/iapgos.1608.

Wilk-Jakubowski, J., 2021: Analysis of Flame Suppression Capabilities Using Low-Frequency Acoustic Waves and Frequency Sweeping Techniques. Symmetry, 13(7), 1299. doi.org/10.3390/sym13071299.

Yi, E.-Y., Bae, M.-J., 2017: A study on the directionality of sound fire extinguisher in electric fire. Converg. Res. Lett. Multimed. Serv. Converg. Art Humanit. Sociol., 3, 1449-1452.

Zhang, X., 2018: Simple understanding of Mask RCNN, Medium, medium.com/@alittlepain833/simple-understandingof-mask-rcnn-134b5b330e95 (12 May 2021). 